\title{
Inversion of wave parameters to perform spectral recomposition
}

\author{
Nelson Ricardo Coelho Flores Zuniga* (IAG-USP)
}

Copyright 2016, SBGf - Sociedade Brasileira de Geofísica

Este texto foi preparado para a apresentação no VII Simpósio Brasileiro de Geofísica, Ouro Preto, 25 a 27 de outubro de 2016. Seu conteúdo foi revisado pelo Comitê Técnico do VII SimBGf, mas não necessariamente representa a opinião da SBGf ou de seus associados. É proibida a reprodução total ou parcial deste material para propósitos comerciais sem prévia autorização da SBGf.

\section{Abstract}

The seismic attributes associated with frequencies are important to characterize stratigraphic sequences and hydrocarbon reservoirs. The spectral recomposition is a technique to extract wave parameters as frequencies and amplitudes of the components of a seismic spectrum.

The spectral recomposition to recover the frequencies and its associated amplitudes (weights) was performed as an inverse problem by an optimization criterion. The analyses of sensibility, unicity and stability were also performed.

With the frequencies and amplitudes recovered, the spectral recomposition showed to be an efficient way to reach a better characterization of a stratigraphic model. With the sensibility analysis, the frequencies which are more difficult to be recovered were determined. The complexity of the objective function was studied analyzing the unicity and the stability of the function.

\section{Introduction}

When the seismic signal is received with each set of frequencies, there is a great possibility of have a better resolution. The fact of have a complete knowledge of each frequency of a spectrum is important to stratigraphic characterization and hydrocarbon reservoir characterization (Castagna et al., 2003; Li et al., 2011). Another possible and useful application is to select frequency bands to perform noise filtering.

The technique called spectral decomposition was strongly studied since it was created (Dilay and Eastwood, 1995; Chakraborty and Okaya, 1995; Partyka et al., 1999; Liu, 2006; Chen et al., 2008; Liu et al., 2011). This technique was usually executed by a time-frequency analysis. Differently of the other approaches, Tomasso et al. (2010) proposed a method which recomposes single frequencies into a multi-frequencies model, and not decomposing the frequencies. The limitation of this approach is associated to the manual pick of each set of frequencies and amplitudes (weights). To overcome this situation, Cai et al. (2013) propose an automatic estimation of linear and nonlinear parts of the Ricker wavelet spectrum based on nonlinear estimation of Golub and Pereyra (1973).
The representation of a seismic spectrum was made by the sum of different Ricker components and uses the Nelder-Mead algorithm (Nelder and Mead, 1965) as the optimization criterion. The spectral recomposition was treated as an inverse problem aiming to estimate the peak frequency and its correspondent amplitude (weight) of each component.

\section{Method}

Tomasso et al. (2010) described a seismic spectrum as a sum of different Ricker components (Equation 1).

$$
d(f) \approx \sum_{i=1}^{n} a_{i} \psi_{i}\left(m_{i}, f\right)
$$

The spectrum of a seismic trace is represented by $d(f), f$ is the vector of frequency, $m_{i}$ is the peak frequency of a determined Ricker spectrum component and $a_{i}$ is the amplitude of each determined component (Equation 2).

$$
R(f)=a \psi(m, f)=a \frac{f^{2}}{m^{2}} \exp \left(-\frac{f^{2}}{m^{2}}\right)
$$

This is a linear combination of the Ricker wavelet spectra with nonlinear functions which depend on two vectors of parameters, the vector of frequencies and the vector of correspondent amplitudes (weights). Here, it has been treated as a single vector of parameter containing both vectors to perform a more efficient inversion.

At first, it must be studied the sensibility of the parameters to identify the difficulty of recover each frequency and amplitude (weight). The sensibility analyses were performed by perturbed parameters and by decomposition in singular values.

Due to the fact of the problem has many variables, it must be treated as an inverse problem by an optimization criterion (Bokhonok, 2010; Zuniga et al., 2015). The optimization algorithm used here was Nelder-Mead (Nelder and Mead, 1965). An important analysis performed here was the study of stability and unicity to identify the complexity of the objective function.

The spectrum model used in this work is composed by five pairs of frequencies ( $\mathrm{m} 1, \mathrm{~m} 2, \mathrm{~m} 3, \mathrm{~m} 4$ and $\mathrm{m} 5$ ) and amplitudes (a1, a2, a3, a4 and a5): $\mathrm{m} 1=2 \mathrm{~Hz}$ and $\mathrm{a} 1=0.8$, $\mathrm{m} 2=5 \mathrm{~Hz}$ and $\mathrm{a} 2=0.7, \mathrm{~m} 3=8 \mathrm{~Hz}$ and $\mathrm{a} 3=0.5, \mathrm{~m} 4=12 \mathrm{~Hz}$ and $\mathrm{a} 4=0.3, \mathrm{~m} 5=15 \mathrm{~Hz}$ and $\mathrm{a} 5=0.1$. 
The model is represented by a Ricker wavelet spectrum with random noise (Figure 1) and after the Fourier transform as a frequencies spectrum (Figure 2).

\section{Results}

Analyzing Figure 3 , it is clearly observed that the amplitudes have a greater sensibility than the frequencies.

It can be observed that the amplitudes are better defined in eigenvector in data space than the frequencies, and the definition of parameters is decreasing with the increase of frequency (Figure 4 and Figure 5).

It can be also observed that the singular values of frequencies are much lower than the values of amplitudes. The eigenvector in parameters space shows a good definition of all frequencies and amplitudes (Figure 4 and Figure 5).

Concerning to the unicity of this model, it can be observed that there are many solutions for this inverse problem (Figure 6). It shows a good stability as it can be observed the similarity of the distribution structures of the associated histograms (Figure 6).

The calculated curve can be seen with a good fitting to the observed curve (Figure 7) and the residual error does not exceed the order of $10^{-2}$ (Figure 8).

\section{Conclusions}

Concerning to the sensibility analysis with perturbed parameters, it can be seen that the frequencies are much more difficult to be recovered.

The good definition of amplitudes in the eigenvectors in data space defines the ease of the parameters recovering.

Even with the parameters well defined in eigenvector in parameters space, the low singular value of frequencies limits the sensibility of the parameters causing some problems to recover the values of these frequencies.

An important factor is the difficulty to recover higher frequencies and amplitudes associated with higher frequencies. Therefore, the low frequencies are better recovered than the higher ones.

Even with a difficulty to find some parameters, all of them were well recovered with a low error.

The results obtained in this work show the efficiency of this method combined with this inversion routine to perform a spectral recomposition.

In future works, it is important to analyze more precisely the influence of high frequencies in the difficulty of the parameters recovering.

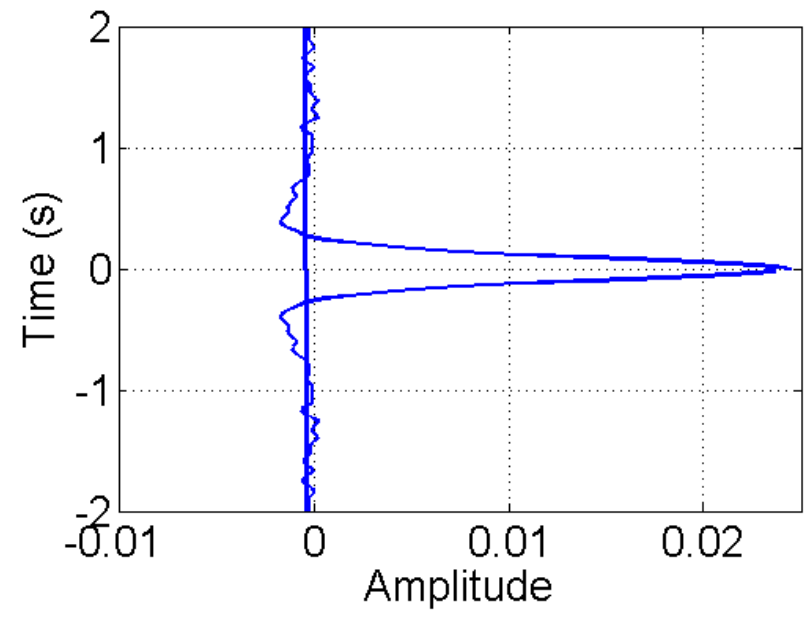

Figure 1: Ricker wavelet spectrum of the model on time domain with random noise.

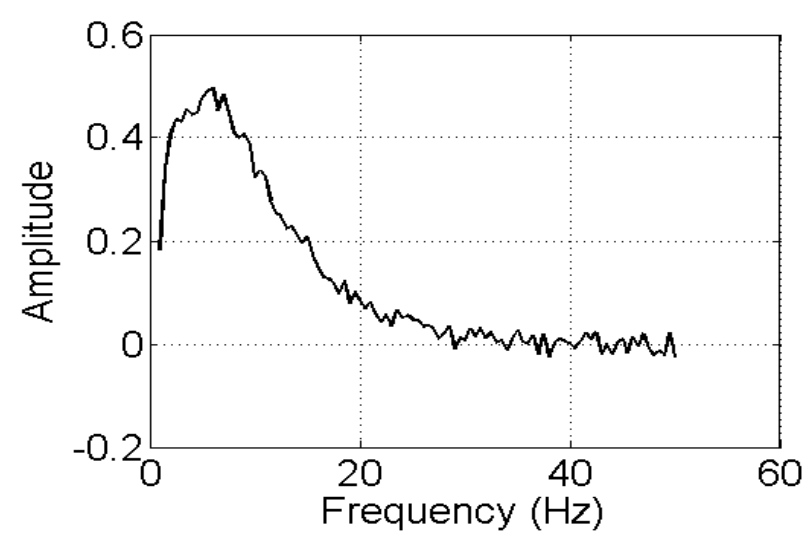

Figure 2: Frequencies spectrum of the model with random noise.



Figure 3: Frequencies spectra of the model without noise, and with perturbations in each frequency (solid lines) and each correspondent amplitude (weight) (dotted lines) focusing the sensibility analysis with perturbed parameters (perturbation of $1 \%$ in each parameter). 
(a)


(b)
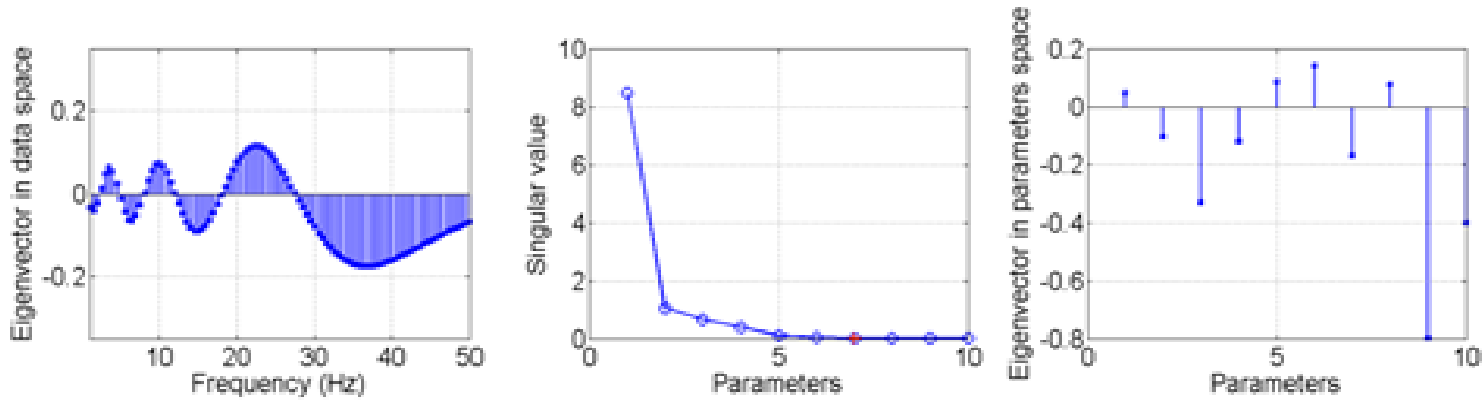

(c)
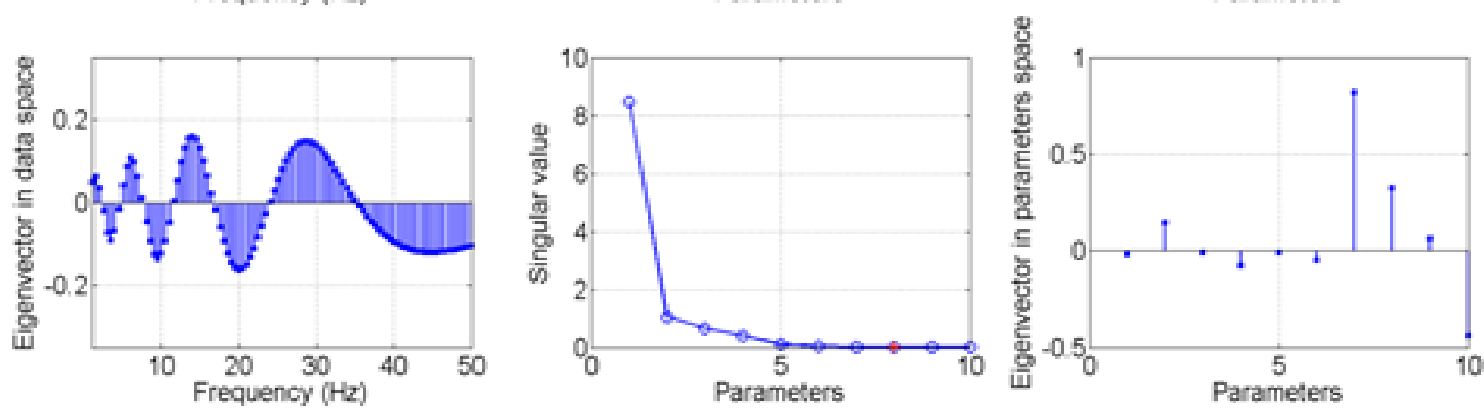

(d)
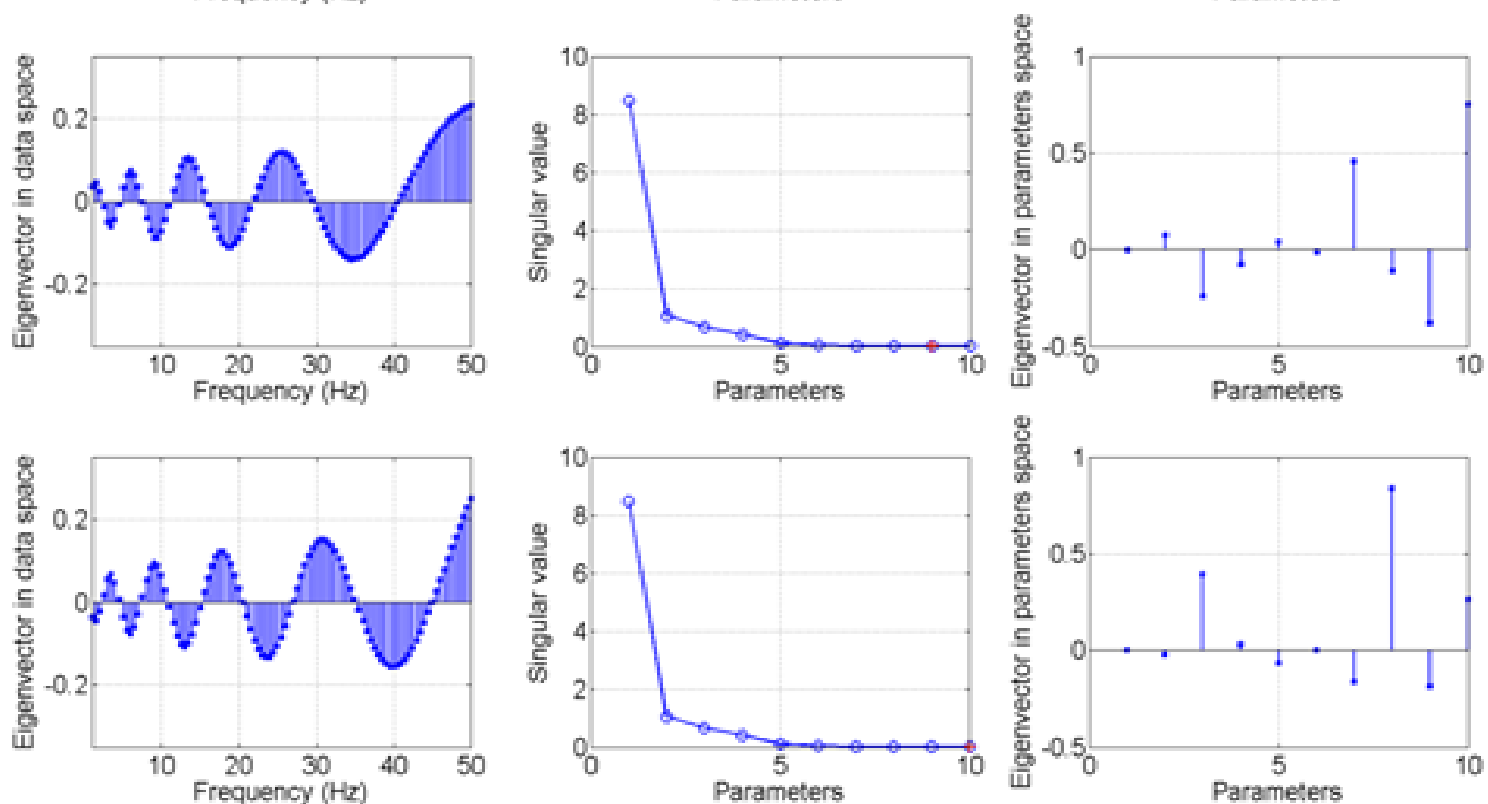

Figure 4: Sensibility analysis using decomposition in singular values for frequencies (a) m1, (b) m2, (c) m3, (d) m4 and (e) $\mathrm{m5}$. The eigenvector in the data space on the left column, the singular value on the middle column and the eigenvector in the parameters space on the right column. 
(a)


(b)


(c)
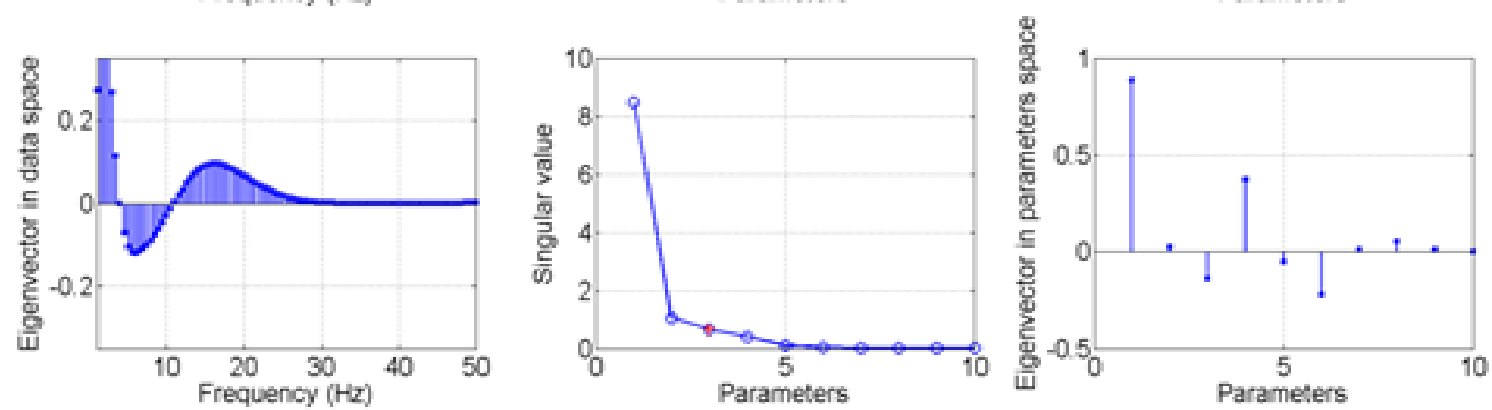

(d)
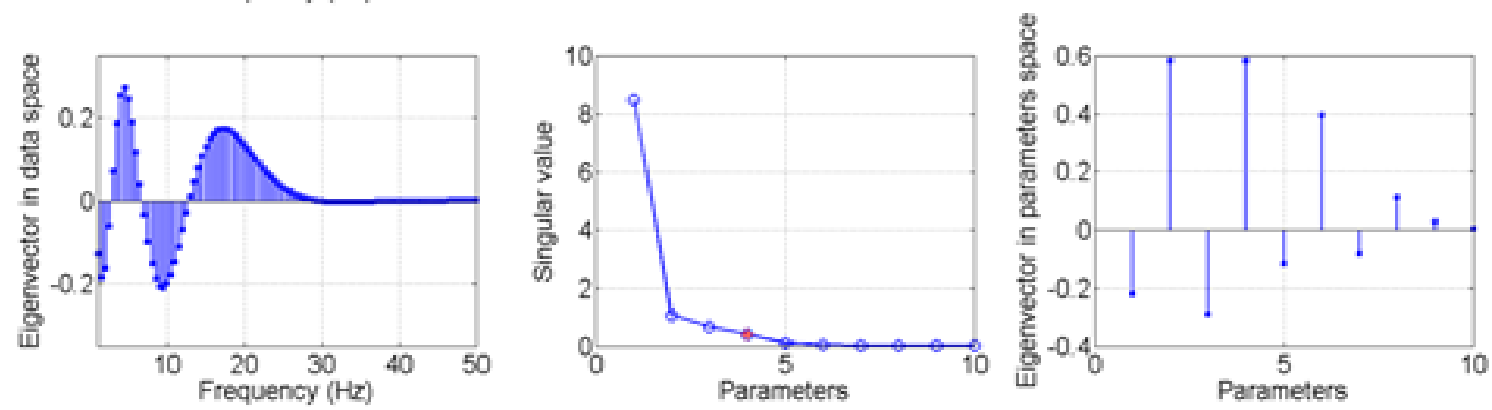

(e)
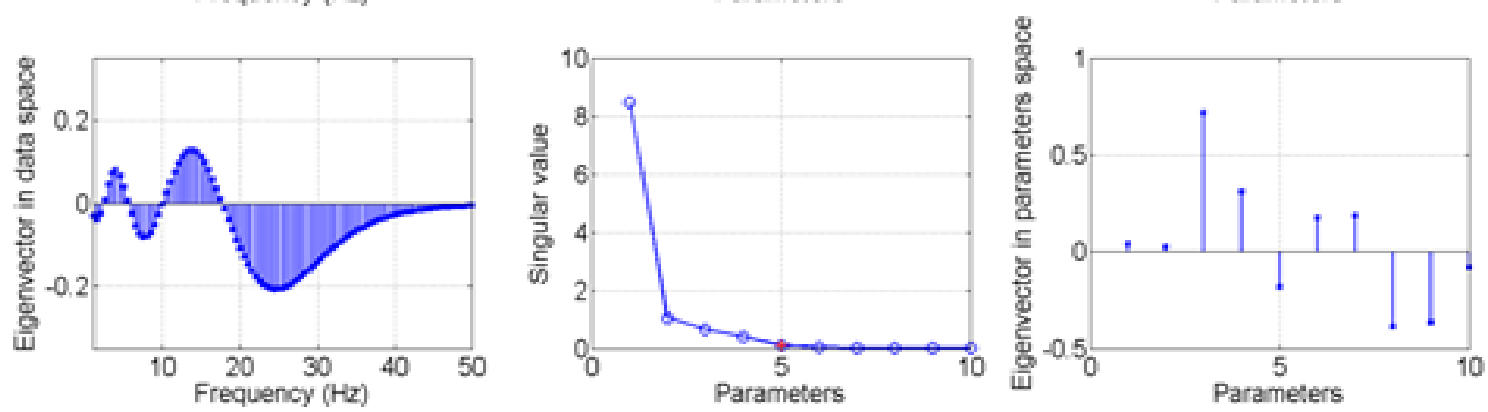

Figure 5: Sensibility analysis using decomposition in singular values for amplitudes (weights) (a) a1, (b) a2, (c) a3, (d) a4 and (e) a5. The eigenvector in the data space on the left column, the singular value on the middle column and the eigenvector in the parameters space on the right column. 
(a)

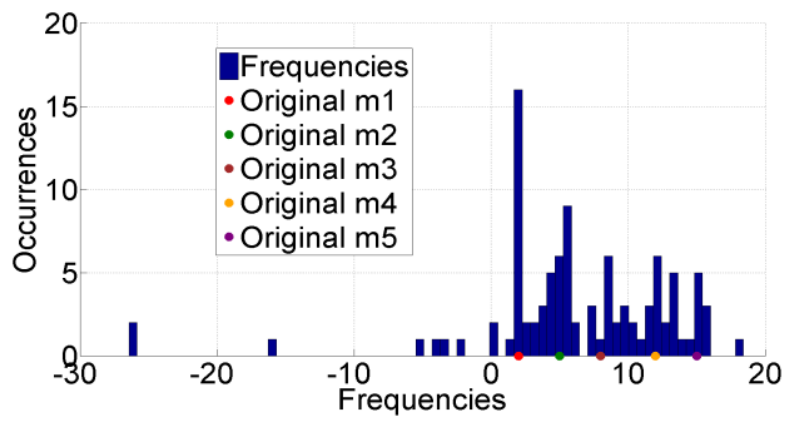

(b)

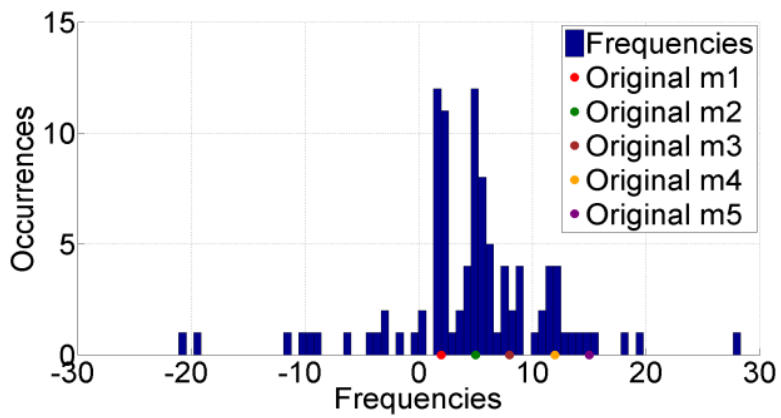

(c)

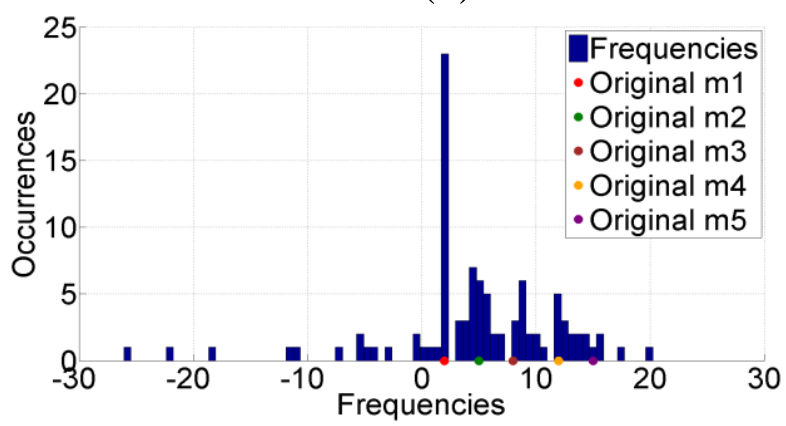

(d)



(e)

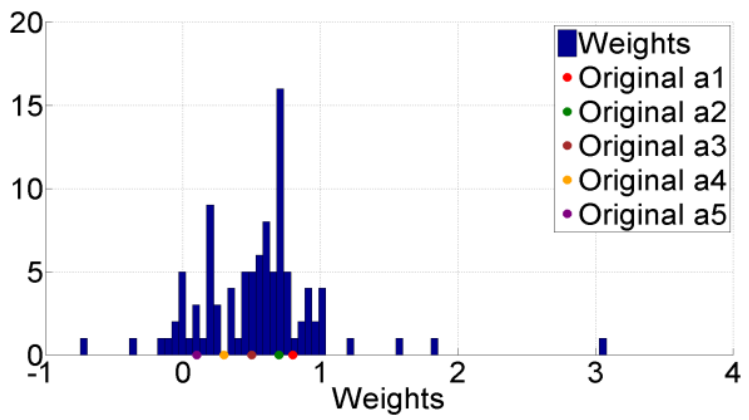

(f)

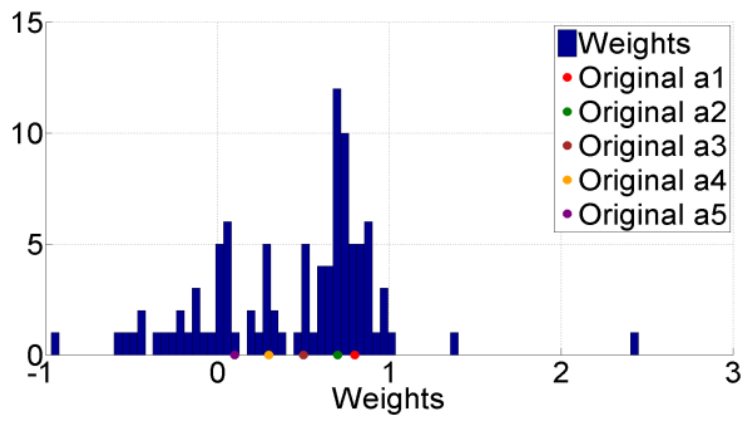

(g)

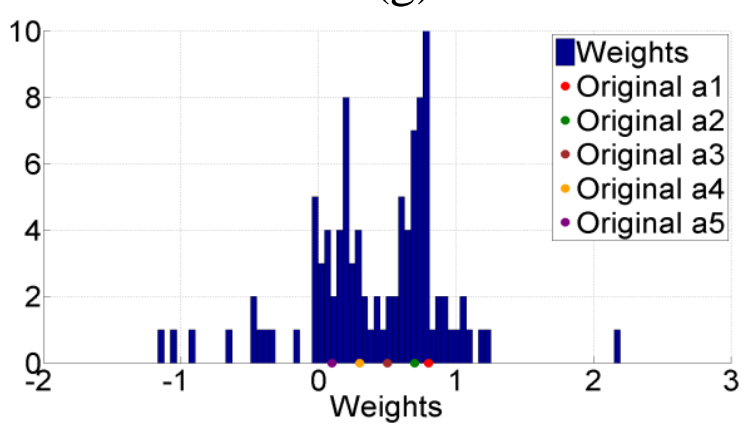

(h)

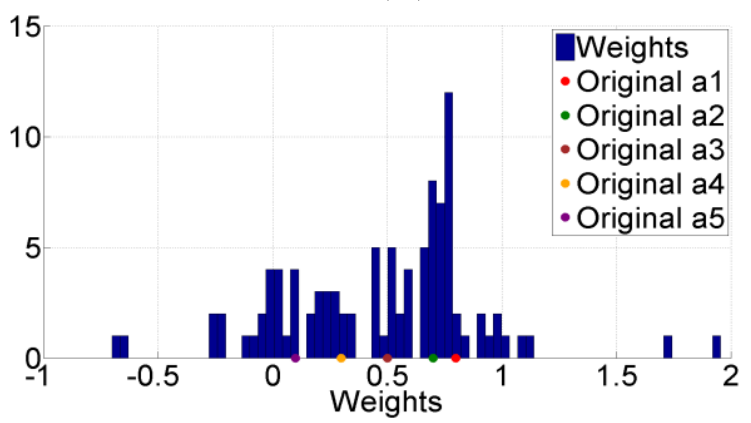

Figure 6: Histogram showing the distribution of occurrences of each interaction of the four inversion routines. In the left column is shown the distribution of occurrences of the frequencies of the (a) first, (b) second, (c) third and (d) fourth inversion routines. In the right column is shown the distribution of occurrences of the amplitudes (weights) of the (e) first, (f) second, (g) third and $(\mathrm{h})$ fourth inversion routines. 


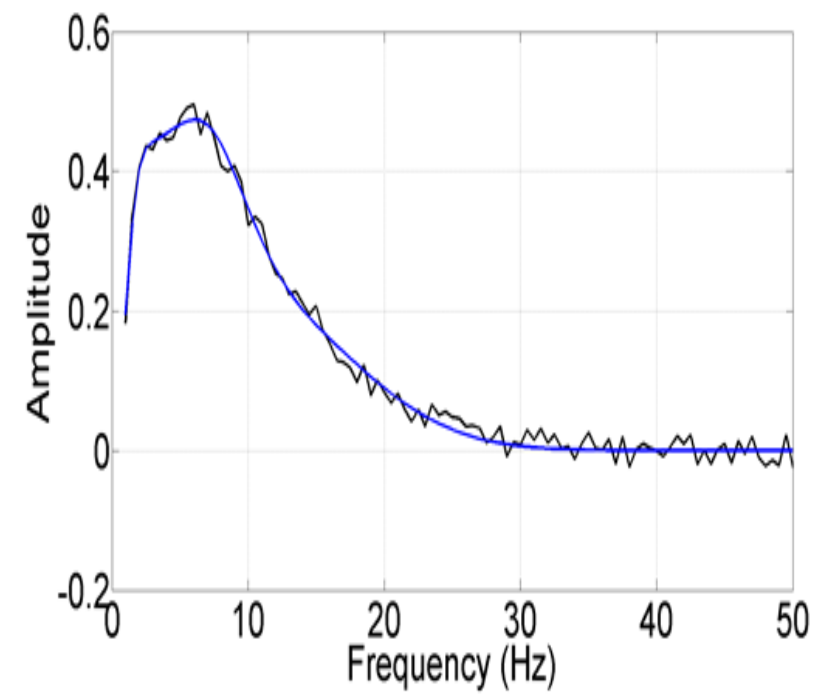

Figure 7: Curve fitting between the observed curve and the calculated curve with the inversion routine.

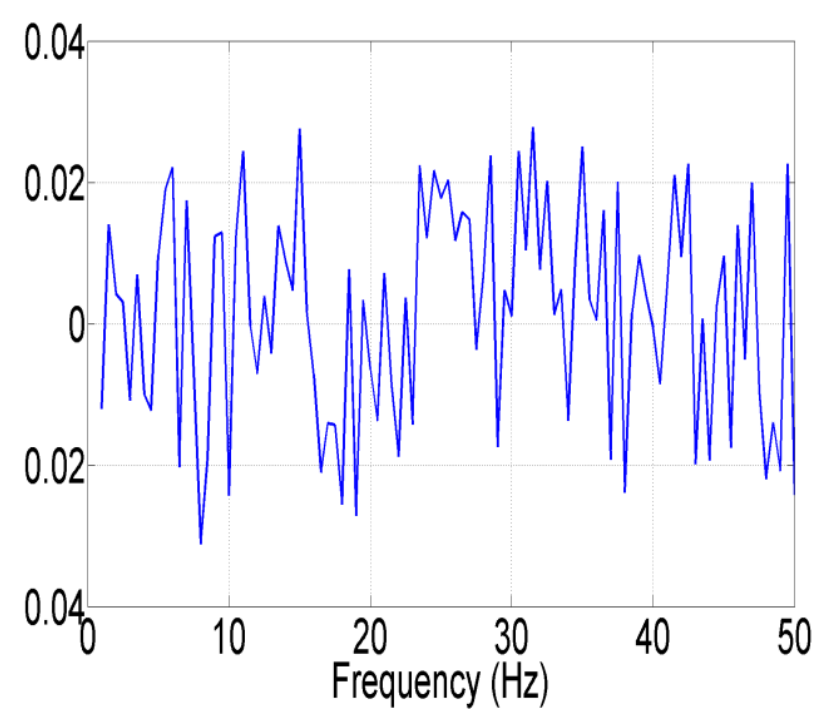

Figure 8: Residual amplitude between the observed curve and calculated curve.

\section{References}

BOKHONOK, O. Sísmica de reflexão rasa multicomponente: Aquisição e inversão de tempos de trânsito e amplitudes. Doctoral thesis. Universidade de São Paulo, 2010.

CAI, Y; FOMEL, S; ZENG, H. Automated spectral recomposition with application in stratigraphic interpretation. Interpretation. 1, 109-116, 2013.

CASTAGNA, J. P.; SUN, S; SIEGFRIED, R. W. Instantaneous spectral analysis: Detection of lowfrequency shadows associated with hydrocarbons. The Leading Edge, 22, 120-127, 2003.

CHAKRABORTY, A.; OKAYA, D. Frequency-time decomposition of seismic data using wavelet-based methods. Geophysics, 60, 1906-1916, 1995.
CHEN, G.; MATTEUCCI, G.; FAHMY, B.; FINN, C. Spectral-decomposition response to reservoir uids from a deepwater West Africa reservoir. Geophysics, 73, C23-C30, 2008.

DILAY, A.; EASTWOOD, J. Spectral analysis applied to seismic monitoring of thermal recovering. The Leading Edge, 14, 1117-1122, 1995.

GOLUB, G. H.; PEREYRA, V. The differentiation of pseudo-inverses and nonlinear least squares problems whose variables separate. Numerical Analysis, 10, 413-432, 1973.

LI, Y.; ZHENG, X.; ZHANG, Y. High-frequency anomalies in carbonate reservoir characterization using spectral decomposition. Geophysics, 76, V47-V57, 2011.

LIU, G.; FOMEL, S.; CHEN, X. Time-frequency analysis of seismic data using local attributes. Geophysics, 76, P23-P34, 2011.

LIU, J. Spectral Decomposition and Its Application in Mapping Stratigraphy and Hydrocarbons. PhD thesis, Univeristy of Houston, 2006.

NELDER, J. A; MEAD, R. A simplex method for function minimization. The Computer Journal, v. 7, p. 308-313, 1965.

PARTYKA, G. J.; GRIDLEY, J.; LOPEZ, J. Interpretational applications of spectral decomposition in reservior characterization. The Leading Edge, 18, 353360, 1999.

TOMASSO, M.; BOUOULLEC, R.; PYLES, D. R. The use of spectral recomposition in tailored forward seismic modeling of outcrop analogs. AAPG Bulletin, 94, 457474, 2010.

ZUNIGA, N. R. C. F.; BOKHONOK, O.; DIOGO, L. A. Comparison of nonhyperbolic travel-time approximations for multicomponent seismic data. In: 14th SBGf Congress, Expanded Abstract, p. 1176$1181,2015$. 